\title{
The species of Grammostola (Araneae: Theraphosidae) from Central Argentina: taxonomy, distribution, and surface ultrastructure of coxal setae
}

\author{
N. FERRETTI ${ }^{1}$, G. POMPOZZI ${ }^{2} \&$ F. PÉREZ-MILES ${ }^{3}$ \\ ${ }^{1}$ Centro de estudios parasitológicos y de vectores (CEPAVE) (CCT-CONICET-La Plata), Calle 2 N 584, (1900) La Plata, Argentina. \\ E-mail: nelsonferretti@hotmail.com \\ ${ }^{2}$ Universidad Nacional del Sur, Dpto. de Biología, Bioquímica y Farmacia, San Juan 670, (8000) Bahía Blanca, Argentina \\ ${ }^{3}$ Facultad de Ciencias, Sección Entomología, Iguá 4225, (11400) Montevideo, Uruguay
}

\begin{abstract}
Three species of Grammostola (Araneae, Mygalomorphae, Theraphosidae) from central Argentina are redescribed and illustrated and their geographic distributions are reported. A new synonymy between G. vachoni Schiapelli \& Gerschman 1961 and G. schulzei (Schmidt 1994) n. syn. is proposed. We did not find zones of co-occurrence with the three species but, in several localities, we found two Grammostola species in sympatry. The surface ultrastructure of three types of coxal setae was studied by scanning electron microscopy (SEM). Two morphological types of spiniform setae were found on the coxae. The first type consisted of short and strong piriform setae, with the surface completely covered by ridges, and the second type consisted of long and thinner spiniform setae, with a piriform basal portion. The basal portion of the setae had ridges, the central portion was smooth and the apical zone had numerous short barbs with curved tips. The different types of setae found in these Grammostola species are clearly distinguished, and could be new useful character to diagnose at least these species. In combination with other characteristics, these characters could probably help to solve the problems in other species of this difficult genus if not also other genera.
\end{abstract}

Key words: Neotropical, Argentina, theraphosids, spider taxonomy, new synonymy, setae morphology

\section{Introduction}

The family Theraphosidae is comprised of mostly large-sized mygalomorph spiders. The subfamily Theraphosinae is exclusive to the New World and includes almost half of the 900 species described in the family. Spiders of the genus Grammostola Simon 1892 inhabit temperate South America and the genus currently includes 21 species described throughout Argentina, Uruguay, Chile, Brazil, Bolivia and Paraguay (Platnick 2009). At this time, there are 13 species cited for Argentina and four of them occur in Buenos Aires province (Central Argentina): G. vachoni Schiapelli \& Gerschman 1961; G. schulzei (Schmidt 1994); G. doeringi (Holmberg 1881) and G. burzaquensis Ibarra-Grasso 1946.

Grammostola has presented a taxonomic challenge. The color pattern helps to differentiate live specimens of one species from another but coloration is usually lost when preserved. Bücherl (1951) recognized only four species based on morphometric relationships of the appendages, and later Schiapelli \& Gerschman (1961) proposed six valid species for Argentina based on genital characters, such as the form of male palpal organs and spermathecae. The differences between Grammostola species usually reflect mostly that male palpal organs were observed in different position making the comparison among species difficult. In addition, G. doeringi was not included in the analysis of the species from Argentina (Schiapelli \& Gerschman 1961). Grammostola burzaquensis is present in Buenos Aires province but no data have been published since Ibarra-Grasso $(1946 ; 1961)$. The taxonomy of this group has not received formal attention since Schiapelli \& Gerschman (1961). Recently, more species from Argentina have been described but without information about distribution or even type locality (e.g., Schmidt 2003; Schmidt 2004; Schmidt 2005). Schmidt (1994a) described the genus Polyspina and its single species, Polyspina schulzei based on a single female from an unknown locality, presumed to be Africa equatorial, Madagascar or 